CARDIOVASCULAR MEDICINE

\title{
Improving secondary prevention in coronary bypass patients: closing the audit loop
}

\author{
T N Martin, R J Irving, M Sutherland, K Sutherland, P Bloomfield
}

Heart 2005;91:456-459. doi: 10.1136/hrt.2003.031989

See end of article for authors' affiliations

.....................

Correspondence to: Dr Peter Bloomfield Department of Cardiology, Royal Infirmary, 51 Little France Crescent, Little France, Edinburgh EH16 4SU, UK; peter.bloomfield@ luht.scot.nhs.uk

Accepted 29 June 2004
Objectives: To complete the audit loop assessing secondary preventative care of patients who had had coronary artery bypass graft (CABG) surgery.

Design: Two separate surveys of 1000 patients who had had CABG at the regional centre between 1988 and 1997, selected in 1998 and 2001. A single page questionnaire was sent to the patient's general practitioner.

Interventions: A list was sent to each general practice in Lothian, Scotland, of their patients on the CABG database and the results of the original survey. Lothian Health organised a project to contact and recall patients with cardiac disease in each practice. Sixty five (of 128) practices participated.

Main outcome measures: Blood pressure, smoking status, serum cholesterol concentrations, and prescription of lipid lowering drugs and aspirin.

Results: 918 questionnaires (92\%) in the second survey were returned describing 875 patients: 151 (17\%) patients smoked and 752 patients (86\%) took aspirin. Mean (SD) systolic blood pressure was lower in the second survey (142.5 (19.2) $\mathrm{mm} \mathrm{Hg}$ in the first survey $v 139.4$ (19.1) mm Hg, p < 0.005). In our first survey $34 \%$ of patients had cholesterol concentrations less than target $(5.2 \mathrm{mmol} / \mathrm{l})$. This increased from $12 \%$ of patients operated on in 1988 to $50 \%$ of patients operated on in 1997 (Spearman rank correlation $0.77, p<0.01)$. In the second survey this proportion had risen to $65 \%$ and the correlation with year of operation was abolished.

Conclusions: By closing the audit loop, substantial improvements were shown in the management of risk factors in patients who have had coronary artery surgery in Lothian.
$\mathrm{P}$ ublished surveys have shown that a substantial proportion of patients with coronary heart disease do not receive optimal secondary preventative care. ${ }^{12}$ In an audit of 1000 randomly selected patients in Lothian, Scotland, who had undergone coronary artery bypass graft (CABG) surgery between 1988 and $1997,{ }^{3}$ we found that $85 \%$ of patients were taking aspirin but $11 \%$ continued to smoke, $13 \%$ had blood pressure control above target levels, and $60 \%$ had higher than recommended cholesterol concentrations. Patients who had their surgery before publication of the landmark statin studies ${ }^{4-6}$ were significantly more likely to have cholesterol above target concentrations suggesting that they were a "forgotten population".

Following that audit, two local interventions, one a collaboration between primary and secondary care and one based in primary care, have attempted to improve management of risk factors in these patients. We have closed the audit loop and here describe the results from a survey of a further 1000 randomly selected patients who have had CABG surgery in Lothian.

\section{METHODS}

\section{Audits}

We selected patients with Lothian postcodes at random from the cardiac surgical database at the Royal Infirmary of Edinburgh, the regional centre for cardiac surgery. The original audit included patients whose operations were between 1988 and 1997 inclusive. Our current audit took a further random selection of patients from these years and, in addition, examined patients from 1998 to 1999. Both audits included 1000 patients.

For each audit the same single page questionnaire was sent to the patient's general practitioner. We requested information on aspirin treatment, smoking status, measurement and treatment of high blood pressure, and measurement and treatment of plasma cholesterol.

\section{Interventions}

Two specific interventions to improve the care of patients with coronary disease ran concurrently between the first and second audits.

- To each general practice in Lothian we sent a list of all their own patients who had had CABG surgery. We enclosed a summary of the results of the original audit. We also asked a single question: "Is it useful to receive this list of patients from your practice?"

- Since 1996 the Lothian General Practice Audit Committee (GPAC) has offered an audit support project to general practices in Lothian looking at the management of hyperlipidaemia (the recording of risk factors and the implementation of local guidelines) in patients with ischaemic heart disease. A pilot in 1996 involved 10 practices. Further development of the audit support project since 1998 has resulted in 86 practices (of a possible 128) completing the first phase, with 65 practices completing a second round about one year later (the audit support project is ongoing). Funding was made available to support practices in the extra work involved and a stand alone electronic tool was developed to facilitate data collection and analysis. The electronic tool is available from the Clinical Effectiveness Unit, Stevenson House, Edinburgh EHIl 3LG, UK.

Abbreviations: CABG, coronary artery bypass graft; EUROASPIRE, European action on secondary prevention through intervention to reduce events; GPAC, General Practice Audit Committee 
Table 1 Recording of risk factors by general practitioners in two surveys of 1000 patients undergoing $\mathrm{CABG}$ randomly selected from the cardiac surgery database

\begin{tabular}{|c|c|c|c|}
\hline & \multicolumn{2}{|l|}{ Survey } & \multirow[b]{2}{*}{ p Value* } \\
\hline & 1998 & 2001 & \\
\hline Completed questionnaire & $761(76 \%)$ & $918(92 \%)$ & 0.01 \\
\hline Alive & $563(74 \%)$ & $875(95 \%)$ & 0.005 \\
\hline \multicolumn{4}{|l|}{ Smoking status } \\
\hline Current smoker & $65(12 \%)$ & $151(17 \%)$ & 0.02 \\
\hline Former smoker & $210(37 \%)$ & $288(33 \%)$ & 0.02 \\
\hline Non-smoker & $223(40 \%)$ & $381(44 \%)$ & 0.02 \\
\hline $\begin{array}{l}\text { GP unaware of } \\
\text { smoking status }\end{array}$ & $65(12 \%)$ & $57(7 \%)$ & 0.01 \\
\hline Aspirin use & $456(81 \%)$ & $747(85 \%)$ & 0.02 \\
\hline \multicolumn{4}{|l|}{ Blood pressure recording } \\
\hline Blood pressure recorded & $552(98 \%)$ & 864 (99\%) & 0.93 \\
\hline Most recent record (days) & $305(460)$ & $251(333)$ & 0.02 \\
\hline Systolic (mm Hg) & $142.5(19.2)$ & $139.4(19.1)$ & 0.005 \\
\hline Diastolic (mm Hg) & $80.6(9.3)$ & $77.7(10.2)$ & 0.001 \\
\hline $\begin{array}{l}\text { Treated systolic } \\
\quad>140 \mathrm{~mm} \mathrm{Hg}\end{array}$ & $260(46 \%)$ & $350(40 \%)$ & 0.15 \\
\hline $\begin{array}{l}\text { Untreated systolic } \\
>140 \mathrm{~mm} \mathrm{Hg}\end{array}$ & $17(3)$ & $14(1.6)$ & 0.8 \\
\hline \multicolumn{4}{|l|}{ Cholesterol } \\
\hline Recorded & $472(84 \%)$ & $817(89 \%)$ & 0.17 \\
\hline Most recent record (days) & 491 (601) & $427(700)$ & 0.001 \\
\hline Drug prescribed & $279(50 \%)$ & $615(70 \%)$ & 0.001 \\
\hline Treated to target & $191(34 \%)$ & $572(65 \%)$ & 0.02 \\
\hline Untreated and below target & $130(23 \%)$ & $63(7 \%)$ & $<0.001$ \\
\hline Concentrations (mmol/l) & $5.46(1.07)$ & $4.82(0.90)$ & $<0.001$ \\
\hline \multicolumn{4}{|c|}{$\begin{array}{l}\text { Data are mean (SD) or number of patients (\%). } \\
\text { *1998 versus } 2001 \text { audit data. }\end{array}$} \\
\hline & & & \\
\hline
\end{tabular}

\section{Statistical analysis}

Continuously distributed variables are expressed as mean (SD) and comparisons were made with $t$ tests. Categorical data were analysed with $\chi^{2}$. All statistical tests were performed with Statistica 6.0 (Statsoft Inc, Tulsa, Oklahoma, USA). A probability value of $p<0.05$ was considered significant.

\section{RESULTS}

Both audits had excellent response rates. There were small but significant changes in rates of aspirin use, smoking status, and blood pressure control (table 1). Recorded systolic and diastolic blood pressure were lower in the second audit than in the first. Few patients who had systolic pressure measured at greater than $160 \mathrm{~mm} \mathrm{Hg}$ were not prescribed drugs in both audits. In the 1998 audit 46\% (260 patients) had systolic blood pressure exceeding the more modern target of $140 \mathrm{~mm} \mathrm{Hg}$ compared with $40 \%$ (350 patients, $\mathrm{p}=0.15)$ in the second audit.

\section{Cholesterol treatment}

Between the two audits the contemporaneous target concentration for treatment was reduced from $5.2 \mathrm{mmol} / \mathrm{l}$ to $5.0 \mathrm{mmol} / \mathrm{l}$; for ease of comparison we have used the higher figure but results were comparable whichever target figure was used.

Cholesterol concentrations were lower and had been measured more recently in the second audit. Cholesterol lowering treatment was prescribed to more patients, more patients were treated to target, and fewer patients had untreated cholesterol concentrations that were greater than the threshold for treatment (table 1).

In the first audit in 1998 only 34\% of patients had a cholesterol concentration less than the contemporaneous target of $5.2 \mathrm{mmol} / \mathrm{l}$. This proportion was significantly lower for patients who had had CABG several years previously: $12 \%$ for patients who had their CABG in 1988 compared with 50\% of those who had their CABG in 1997 (p < 0.01) (fig 1). In the second audit the overall proportion achieving this target had risen to $65 \%$ (572 patients) and we found no difference in the proportion of patients achieving this target according to the year of their operation (fig 2).

\section{Practices participating in Lothian general practice} audit project compared with usual care in 2001 audit Sixty five practices of a total of 128 took part in the project sponsored by Lothian GPAC to call and recall patients with ischaemic heart disease. We found no difference in prescription of aspirin or in smoking between patients attending practices that had participated in the GPAC project and those that had not. Blood pressure had been recorded more recently in the GPAC project practices. Systolic blood pressure was lower in the GPAC practices but diastolic blood pressure was not measurably different between the groups. Cholesterol had been measured more recently in practices that had taken part in the GPAC project and recorded cholesterol concentrations were lower (table 2). Cholesterol concentrations in patients taking cholesterol lowering treatment were significantly lower in the GPAC project $(4.67 v 4.88 \mathrm{mmol} / \mathrm{l}$, $\mathrm{p}=0.002$ ) implying that stronger doses of cholesterol lowering drugs were used. However, the proportion of patients with untreated cholesterol concentrations higher than the 2001 target concentration of $5.0 \mathrm{mmol} / \mathrm{l}$ was no different between practices that had or had not participated in the GPAC project $(12 \% \vee 9.3 \%, \mathrm{p}=0.18)$.

\section{DISCUSSION}

We have shown that the management of risk factors in patients who had had coronary artery surgery in Lothian improved substantially over a three year period. More patients have had their risk factors measured and appropriate treatment instituted and monitored. It is likely that the improvement in blood pressure and cholesterol management between the 1998 and 2001 CABG audits was due in large part to the direct notification to general practitioners of individual patients who had had CABG and who would benefit from secondary prevention. Treatment with lipid lowering drugs clearly improved in patients who had had their coronary surgery before the publication of landmark trials of statins suggesting that this forgotten population had been identified and appropriately treated. More than $70 \%$ of general practitioners responded that notifying them of their own individual patients who had had CABG was helpful; many of the remainder stated they had identified the patients by their own internal audit. Hospital databases of patients who have had CABG, myocardial infarction, or percutaneous coronary intervention are widespread and may easily be used to identify patients no longer attending hospital follow up but who would benefit from secondary prevention such as cholesterol reduction and blood pressure treatment.

These results compare favourably with other recent studies. EUROASPIRE (European action on secondary prevention through intervention to reduce events) II showed an improvement in cholesterol concentrations in a population with coronary disease, but the degree of change was smaller. ${ }^{7}$ Brady and colleagues ${ }^{8}$ recently presented a large scale follow up survey (1999-2002) of 11996 patients with coronary disease for whom statin prescribing remained static. A recent audit of patients admitted for CABG in Manchester found that $45 \%$ had a cholesterol concentration of greater than $5.0 \mathrm{mmol} / \mathrm{l}$ and of these two thirds were receiving lipid lowering drugs. ${ }^{9}$ No lipid lowering drug was being taken by $28 \%$. In an audit in cardiac surgery units in Newcastle and London fewer than half of patients admitted for CABG were receiving a statin on admission. At discharge from the surgical units ${ }^{10}$ after $\mathrm{CABG}$ the proportion receiving a statin 


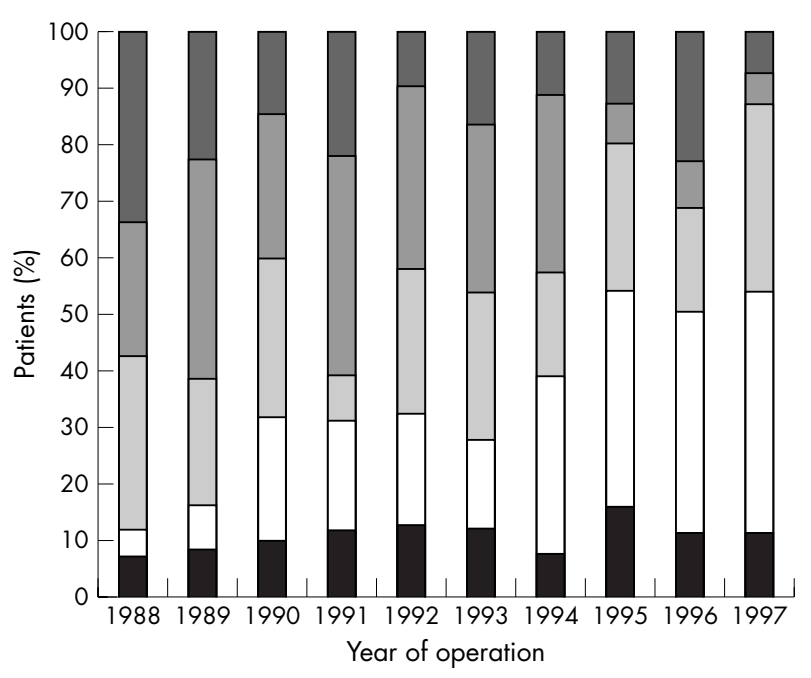

was just as low. Therefore, despite the increase in awareness of the benefits of statins, one cannot assume that all patients who merit treatment are receiving it, and interventions to increase the proportion who do are worthwhile.

The two interventions described in this paper took place over the same time period and it is difficult to distinguish the impact of each. We found that patients of practices that had participated in the Lothian GPAC project were likely to have had their cholesterol and blood pressure measured more recently and levels of these risk factors were both significantly lower. This suggests an additional benefit of the GPAC audit.

While our audit has shown an improvement in management of risk factors the results are still far from ideal. We found that $30 \%$ of patients who had had CABG surgery were not receiving a statin. The heart protection study and other trials ${ }^{4-611}$ have shown that all patients with coronary heart disease benefit from treatment with statins. Furthermore, patients who have undergone CABG have significantly lower rates of graft occlusion and further coronary events if treated with aggressive cholesterol reduction with high doses of statins compared with treatment to conventional target concentrations. ${ }^{6}$ The results of our audit show that too few patients who have had CABG surgery are receiving statins and it is probable that many are receiving too low a dose. Although we did not obtain data on dosage of statins

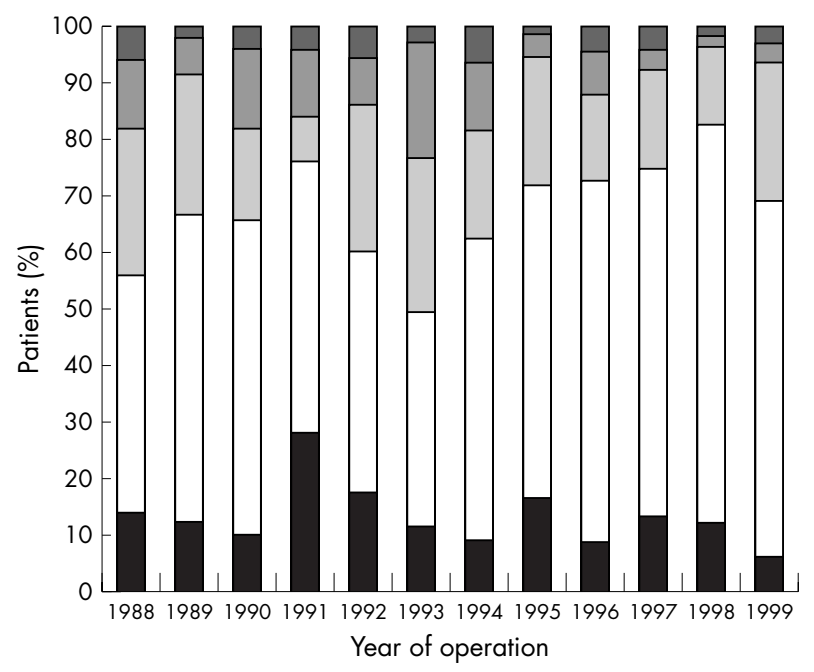

Figure 1 Histogram illustrating the management of serum cholesterol according to year of operation as determined by the 1998 audit. The proportion of patients with a recorded cholesterol concentration less than the target of $5.2 \mathrm{mmol} / /$ rose from $12 \%$ for patients operated on in 1988 to $50 \%$ of patients operated on in 1997. Spearman rank correlation 0.77 , $\mathrm{p}<0.001$. $\geq 5.2 \mathrm{mmol} / \mathrm{l}$ Treated cholesterol $<5.2 \mathrm{mmol} / \mathrm{l}$

Untreated cholesterol $<5.2 \mathrm{mmol} / \mathrm{l}$ prescribed, the proportion of patients with a cholesterol concentration greater than $5.2 \mathrm{mmol} / \mathrm{l}$ and treated with statins suggests that inadequate doses of statins are commonly used. Lothian guidelines on the management of lipid disorders and the Lothian formulary both recommend starting treatment with the lowest dose of statin and titrating to target cholesterol concentrations. ${ }^{12}$ Lothian and national guidelines do not identify patients who have undergone CABG surgery as potentially benefiting from higher doses of statins. ${ }^{12} 13$

Postal questionnaires cannot assess how many patients take their medication. It may well be that some of the patients who are prescribed cholesterol lowering drugs but remain above their targets take less of their medication than patients who are below their targets. It is worth noting that the heart protection study excluded patients who were assessed as not likely to comply after an 8-10 week run-in phase. ${ }^{11}$ Twenty six per cent of patients eligible for the trial were excluded. This large number of patients who keep their own counsel on the value of medication that alters risk and not symptoms may ultimately limit the scope of interventions to improve rates of treatment of cholesterol.

In closing the audit loop we have shown that secondary prevention for patients who have undergone CABG surgery can be improved. There may be diminishing returns from prescribing every drug that offers theoretical risk reduction: a
Figure 2 Histogram illustrating the management of serum cholesterol according to year of operation as determined by the 2001 audit. There was no significant correlation between the proportion of patients with optimal cholesterol and year of operation in the second audit.

\section{$\geq 5.2 \mathrm{mmol} /$}

Treated cholesterol $\geq 5.2 \mathrm{mmol} / \mathrm{l}$

Treated cholesterol $<5.2 \mathrm{mmol} / \mathrm{l}$

Untreated cholesterol $<5.2 \mathrm{mmol} / \mathrm{l}$ 
Table 2 Comparison of blood pressure and cholesterol measurements in the 2001 audit of patients attending practices who had and had not participated in the General Practice Audit Committee (GPAC) programme for review of secondary prevention in patients with coronary heart disease

\begin{tabular}{llll}
\hline & GPAC & Non-GPAC & p Value \\
\hline Total & $482(55 \%)$ & $393(45 \%)$ & ND \\
Blood pressure control & & & \\
$\quad$ Most recent record (days) & $230(299)$ & $278(372)$ & 0.04 \\
$\quad$ Systolic (mm Hg) & $138(18.5)$ & $141(19.7)$ & 0.04 \\
$\quad$ Diastolic (mm Hg) & $77.7(10.3)$ & $77.8(10.0)$ & 0.87 \\
Cholesterol treatment & $389(753)$ & $479(618)$ & 0.08 \\
$\quad$ Most recent record (days) & $4.75(0.86)$ & $4.93(0.95)$ & 0.003 \\
$\quad$ Concentration (mmol/l) & $4 \%$ ) ND, not determined. \\
\hline Data are mean (SD) or number of patients (\%)
\end{tabular}

recent $B M J$ editorial ${ }^{14}$ questioned the incremental value of the "sixth coronary disease drug". However, at present, many patients do not benefit from well established treatments. Databases of patients held in secondary care can usefully be used to support general practitioners in the management of secondary prevention in patients with established coronary heart disease who remain at risk of recurrent events.

\section{ACKNOWLEDGEMENTS}

We acknowledge the general practitioners who completed the surveys and Dr Helen Oram, John Boyd, Dr Fergus McRae, and Dr Philip Rutledge, who contributed to the first phase of the project. The project was supported by an unrestricted grant from Pfizer Ltd.

\section{Authors' affiliations}

T Martin, P Bloomfield, R J Irving, Department of Cardiology, Royal Infirmary, Edinburgh, UK

M Sutherland, Department of Clinical Audit, Royal Infirmary, Edinburgh, UK
K Sutherland, Lothian General Practice Audit Committee, Lothian Health, Edinburgh, UK

\section{REFERENCES}

1 Bowker TJ, Clayton TC, Ingham J, et al. A British Cardiac Society survey of the potential for the secondary prevention of coronary disease: ASPIRE (action on secondary prevention through intervention to reduce events) principal results. Heart 1996;75:334-42.

2 Kosteva K, Wood DA, DeBacker G, et al. Lifestyle and risk factor management and use of drug therapies in coronary patients from 15 countries: principal results from EUROASPIRE II Euro heart survey programme. Eur Heart $J$ $2001 ; 22: 554-72$

3 Irving RJ, Oram SH, Boyd J, et al. Ten year audit of secondary prevention in coronary bypass patients. BMJ 2000;321:22-3.

4 Pedersen TR. Randomised trial of cholesterol lowering in 4444 patients with coronary heart disease: the Scandinavian simvastatin survival study (4S). Lancet 1994;344:1383-9.

5 Sacks FM, Pfeffer MA, Moye LA, et al. The effect of pravastatin on coronary events after myocardial infarction in patients with average cholesterol levels. N Engl J Med 1996;335:1001-9.

6 Campeau L, Knatterud GL, Domanski M, et al. The effect of aggressive lowering of low-density lipoprotein cholesterol levels and low-dose anticoagulation on obstructive changes in saphenous-vein coronary-artery bypass grafts. Benefit of aggressive lipid-lowering therapy: insights from the post coronary artery bypass graft study and other trials. N Engl J Med 1997;336:153-62.

7 EUROASPIRE I and II Group. Clinical reality of coronary prevention guidelines: a comparison of EUROASPIRE I and II in nine countries EUROASPIRE I and II group. Lancet 2001;357:995-1001.

8 Brady AJB, Pittard JB, Grace JF, et al. Four-year sequential review (19992002) of statin treatment in 11,996 patients with established CHD: the Healthwise audit [abstract]. Heart 2003;89:A58.

9 Charalambous C, Cleanthous S, Siddique I, et al. Secondary prevention in patients awaiting CABG in the north west of England. Br J Cardiol 2002;9:488-90.

10 Archbold RA, Zaman AG, Curzen NP, et al. Prescribing of ACE inhibitors and statins after bypass surgery: a missed opportunity for secondary prevention? Br J Cardiol 2003:10:36-43.

11 Heart Protection Study Collaborative Group. MRC/BHF heart protection study of cholesterol lowering with simvastatin in 20536 high-risk individuals: a randomised placebo-controlled trial. Lancet 2002;360:7-22.

12 Lothian Health. Guidelines for the management of lipid disorders. Edinburgh: Lothian Health, 1995.

13 Wood D, Durrington P, Poulter N, et al. Joint British recommendations on prevention of coronary heart disease in clinical practice. Heart 1998;80(suppl):S1-29.

14 Warburton RN. What do we gain from the sixth coronary heart disease drug? BMJ 2003;327:1237-8.

\section{IMAGES IN CARDIOLOGY}

\section{Pericardial tamponade caused by transvenous temporary endocardial pacing}

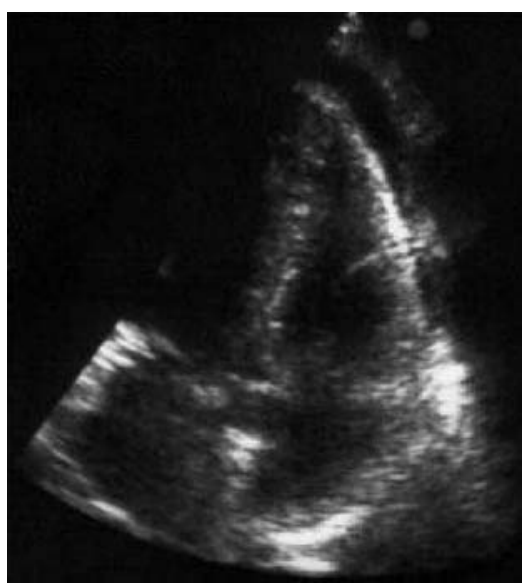

A 65 year old man was admitted because of faintness and syncope. His ECG showed complete atrioventricular block with a heart rate of 30 beats/min. A transvenous temporary pacing electrode was inserted immediately via the right femoral vein. No complications were observed during the procedure. Coronary angiography was performed on the second day because of chest pain, and showed normal coronary arteries. The patient experienced severe chest pain and haemodynamic collapse two hours after coronary angiography. Transthoracic echocardiography demonstrated pericardial tamponade and the pacing electrode wire crossed the free right ventricular wall (panel). Surgical closure of the right ventricular free wall perforation and pericardial drainage was performed. A permanent pacemaker was later inserted without further complication.

Heart perforation caused by a transvenous pacemaker is a rare complication.

M K Erol

S Sevimli

A Ates

mkerol@superonline.com 